\title{
NARCOLEPSY IN CHILDHOOD: A LITERATURE REVIEW
}

\author{
TAKU MURAYAMA ${ }^{1} \&$ MARIA KYOYAMA ${ }^{2}$ \\ IDepartment of Special Needs Education, Tokyo Gakugei University, Tokyo, Japan,takumvn@u-gakugei.ac.jp \\ ${ }^{2}$ School of Education, Tokyo Gakugei University, Tokyo, Japan
}

\section{ABSTRACT}

This study aims to figure out of psychological and physiological features and the special educational needs of school-aged children with narcolepsy through a literature review. In this study, it was stated that difficulties of the narcoleptic children would continue over the long term andalso it is hard to provideappropriate schooling that promotesquality of life of students and enhancesthe students' performance in the schooling. This requires more effective analysisand researchof school liveson a day to day basis. In order to evolve such styles meeting for the patients' needs, it getshighlysignificant for teachers as well as the relative professionals in schooling tounderstanding and assessing their difficulties and performance in the classrooms. Narcolepsy as a medical and pathological condition has been noticed, but in our review, few surveys are found with regard to the needs and support for students with narcolepsy. The researchtarget is to explore the findings as well as problems that have hitherto been increased with regard to analysis on the narcolepsy in childhood and to elucidaterecentdevelopment alsodrawbacks in the analysis of this topic.

KEYWORDS: Narcolepsy, Children, Literature Review, School

Received: Jul 24, 2020; Accepted: Aug 14, 2020; Published: Nov 12, 2020; Paper Id.: IJESRAUG202016

\section{I.INTRODUCTION}

This study aimed to focus on the educational needs of the children with narcolepsy and the effects on modification and accommodation of the illness. Effective support for students with narcolepsy should be putinto action and is mostappropriate for school communities, whichencourages learning and daily lives in schools. There is an emerging consensus that meeting their special educational needs with regards to sleeping disorder should be based on the understanding that their needs should be supported in the active manner with the pedagogical and sociopsychological perspectives. Wise (1998) has pointed out that narcolepsy existence during childhood and waslikely under-recognized in this population, and the key signs of narcolepsy in children were related with adults, however the appearancecan be distinctdue to maturational aspects. This requires an examination of the students' needs with narcolepsy on school settings. Cosgrove (2002) reported that the investigation for teachers' knowledge of narcolepsy and the precision of their understanding founded educators not informed about narcolepsy and how to board narcoleptic students.

In order to develop such an accommodation, modification, and support for students with narcolepsy, it is highlysignificant for teachers and also the relatedprofessionals to mutually understand and jointly reflect on implementations at the classroom and individual level. This was due to teachers and the school professionals may be uninformed about narcolepsy through actual situations of students (Cosgrove 2002, Stores, Montgomery, and Wiggs 2007). Further, understanding and reflection for their needs on practice, if suitablyexecuted, would support students to be suitable for daily lives in schooling, be increasingly effective learning in the classrooms, and draw on 
the work in the school lives to evolve generative framework and effort to createnoticeable most of what is taken for granted about the difficulties also exceptionality with narcoleptic conditions.

\section{II.METHODS}

Literature review is conducted. The present researchutilizes the perspective of a structured literature review of qualitative, quantitative, as well as mixed techniques researches. The literature review utilizeshardtechniquesalsoexamination to recognize, assess and synthesize scientific proof from mainresearchesconcentrating on narcolepsy and their conditions and needs in the schooling. According to Boland et al. (2013) a structured literature review is designed to "locate, appraise, and synthesize" the best available proof that was associated to a specific research question in order to give informed evidencebased solutions. In proof-based practice, a systematic literature review aids teachers and the related professionals in determining whether the proof givenwaspertinent to particular students as it givesappropriate supports and meeting their needs as regards to narcolepsy. The employ of the perspective for this research was pertinent to the research of investigation for students and youth for finding their socio-psychological difficulties in his/her living.

Explores for the present researchhave been completed in the succeeding databases: Education Resources Information Center (ERIC) and PLOS one. These databases are utilized due to the amounts of articles they house and give access to which are pertinent to the subject of research. Search subjects in these databases comprised terms such as "narcolepsy", "childhood", "education", "schooling", and "special needs" in combination with search terms. A second phase manual explorehave beencarried on references of the chosen articles in order to make sure that the potentialfeasiblepertinent articles were recognized. A final internet finding in Google Scholar has been utilized to minimise the feasibility of losing pertinent sources.

\section{III.RESULTS}

\subsection{Treatment for Children with Narcolepsy}

Today, with media campaigns, it's not uncommon to get a narcoleptic sufferer to be diagnosed within a year of onset of this illness or even sooner, 0.025 and $0.40 \%$ in European in addition to North American populations (Nevsimalova et al., 2009). In contrast, the incidence of narcolepsy-cataplexy ranges between 0.16 and $0.59 \%$ in Japan (Itoh, 2013).

The treatment for narcoleptic children has been developing as a method of medical support and the necessity for the treatment has been discussing in a long term. National Clearinghouse for Drug Abuse Information in the National Institute on Drug Abuse (1974) dispenses considerable information on utilize and abuse of the drug family known as amphetamines in the comprehensive report about the medical use of amphetamine. The report also indicates that amphetamine have initially utilized to treat narcolepsy in 1955 , with the discovery three years later that acute paranoid psychosis was a side effect to be guarded against, and that the Canadian government established new controlon amphetamine use as of 1973, in which the drug is restricted to the treatment of narcolepsy hyperkinetic disorder in children, mental retardation (minimal brain dysfunction), epilepsy, parkinsonism, and hypotensive conditions connected with anaesthesia.Weinberg and Emslie (1990) show that therapy for narcolepsy was the tonic medications and for those with depression, protriptyline, and other tricyclic antidepressants and a therapy in combination weresuccessful. In these days, methylphenidate (MPH, ritalin) was broadly employed in humans for therapy of narcolepsy and observation shortfall disorder as the materials with a common effect of amphetamine. Shanker, Syamala, and Kalidindi (2010) also shows supplying elements of discerned rest or sleep loss that requiresadditional examination as cardiovascular disease threat elements comprise occupational elements like 
extended work schedules, jet lag, or shift work, resulting in irregular sleep schedules, and in addition, other sleep disorders such as insomnia, restless legs syndrome, narcolepsy, and circadian rhythm disorders, could lead to sleep loss. In accordance to the suggestion provided by Abraham, Cunningham, and Lattal (2012), the drug could be used in combination with behavioural treatments for sufferers with fear disorders. Sattler, Sauer, Mehlkop, and Graeff (2013) noticedthe relations between the cognitive enhancement and narcolepsy and the relative sleep disorders. Sattler (2013) shows that healthy individuals may perceive cognitive enhancement drug intake as anadvantage-seeking plan to improve their cognitive capabilities, and possible cognitive improving medications involve methylphenidate, (dextro-) amphetamine, donepezil, and modafinil.In the situation that modafinil was a Drug authorized for the therapy of narcolepsy and sleep apnoea along with modafinil had been detailed to be utilized as a pharmacological cognitive enhancer with healthy people without any psychiatric illnesses, Mohamed (2016) reports on a research therapy that researched the impacts of modafinil on divergent and convergent thinking tasks of imagination for the healthy 64 Healthy male $(\mathrm{n}=31)$ and female $(n=33)$ volunteers engaged in a Randomized double-blind placebo-controlled parallel group design research. But a median split evaluation revealed that Modafinil participants reduced in creativity character trait had considerably greater RAT scores (Mean $[\mathrm{M}]=6.85, \mathrm{SD}=3.39 ; 95 \%$ confidence interval $[95 \% \mathrm{CI}]: 5.53-8.2$ ) than those full of creativity personality trait $(\mathrm{M}=4.27, \mathrm{SD}=3.0 ; 95 \% \mathrm{CI}: 2.4-6.0)$. For the divergent thinking activities, relative to placebo $(\mathrm{M}=$ $1.195, \mathrm{SD}=0.28 ; 95 \% \mathrm{CI}: 1.0-1.3)$, modafinil $(\mathrm{M}=0.77, \mathrm{SD}=0.37 ; 95 \% \mathrm{CI}: 0.63-0.92)$ considerably decreased the operation of pliability scores and Marginally decreased the elaboration scores as estimated by the Abbreviated Torrance Test for Adults (ATTA), along with participants on modafinil ( $\mathrm{M}=6.3, \mathrm{SD}=2.6$; $95 \% \mathrm{CI}$ : 5.3-7.4) had considerably lesser ATTA scores relative to participants on placebo $(\mathrm{M}=9.5, \mathrm{SD}=2.3 ; 95 \% \mathrm{CI}$ : $8.6-10.4)$. This research concludes this modafinil may decrease divergent thinking of imagination in healthy people, and modafinil may have negative and subtle impacts on creativity. These medications were prescribed as therapy for various ailments, such as attention deficit hyperactivity disorder (ADHD), postural orthostatic tachycardia syndrome,Alzheimer's disease or dementia, shift work sleep disorder, and narcolepsy (Sattler et al. 2013).

Considering the earlier notice on the treatment, including combined application of drug and psychological therapy for narcoleptic children as same as the other neurological disorders, it is important to concise that the difficulties and needs in the school settings hasattracted less attention.Blackwell et al. (2017) highlights that school-age children with narcolepsy were inconsiderablethreat of cognitive as well as mental impairment, and these impairments were hypothesized to influence on academic performance, standard of life, daytime functioning and safety and therefore these children must be cautiouslyobserved by doctors, parents also teachers.Kornum et al. (2017) shows that many medications were accessible for the symptomatic therapy of narcolepsy, all of which have quite better effectivenessas well asprotective profiles, and enhanced diagnostic instruments and raisedknowledge of the pathogenesis of narcolepsy tare required and maycause to therapeutic or even precautionary involvements.

\subsection{Psychological and Physiological Conditions of Children with Narcolepsy}

Stores, Montgomery, and Wiggs (2007) indicates that narcolepsy is lifelong condition, along with the mental consequences of narcolepsy aren't well reported particularly in children. So as to outline the mental profile of a massive group of children with narcolepsy in comparison with other excessively sleepy kids and controls, they conducted a global cross-sectional questionnaire survey. The poll comprises the recruitment of Children from 4 to 18 years had get a diagnosis of narcolepsy from a doctor in comparison to age- and gender-matched controls. It shows that children with narcolepsy were split into 
people who have fulfilling traditional standards for narcolepsy and people whose key complaint was immoderate daytime sleepiness with no certain extra characteristics of narcolepsy. In response to the results of the international survey, they conclude a variety of mental issues could be recognized in children with narcolepsy, however, the roots of those issues were cloudy.

With regard to leg movement activities during the sleep (LMS), Ferri et al. (2018) compares between LMS limitsdiscovered in school-age and adolescent controls also sufferers with restless legs syndrome (RLS) and narcolepsy type 1. Periodic LMS index alone was not reliably estimate the diagnosis of RLS in children and adolescents. Butexaminationof inter-movement interval distribution as well as time-of-night distribution givesextra factors to help a diagnosis of RLS.

Blackwell et al.(2017) shows the meta-analytic results providing proof to propose that children who create narcolepsy were in considerable threat of cognitive impairment in a minimum of one area and psychological issues like depression, stress and reduced self-esteem, discovering that the issues most frequently noticed from the children are chronic sleepiness, absence of alertness along with absence of attentiveness that were likely to influence cognitive function and might be the root reason for the high levels of academic failure observed within the children with narcolepsy contained in those researches. The results of getting impaired parts of cognitive function (e.g., decision making and focus) in children with narcolepsy could be severe, according to function in the virtual reality surrounding, to ensure narcolepsy in school-age children was a threat element to the progression of heterogeneous cognitive issues that could influence on academic achievement, daytime operation and security (Blackwell et al. 2017). Additionally it shows that children who have narcolepsy ought to be observed cautiously so as to control and lessen the effect of any impairmentthat exists.

\subsection{Complex Conditions with ADHD}

Stores et al (2007) also shows the identical profiles of complications in the narcolepsy and immoderate daytime sleepiness groups propose that immoderate sleepiness is the primary reason. The comparative analysis between narcolepsy and other related symptoms such as the developmental disabilities like as autism, attention deficit hyperactivity disorders (ADHD), and so on. In particular, the surveys for the complication of narcolepsy and ADHD figure prominently in the related articles.

Narcolepsy is regarded as an abnormality of the brain stem property of rapid eye movement (REM) sleep and overrides the right brain functioning of vigilance. Weinberg and Emslie (1990) say that narcolepsy was a rare source of ADHD however has to be regarded in the distinct diagnosis. Surely, narcolepsy was differentiated by unsuitable sleep attacks in connection with hypnogogic hallucinations, sleep paralysis and/or cataplexy. The study also indicates that these were signs of REM sleep conditions happening unsuitably throughout the day, on-going to sleep, onawakeningduringthe night or inthe morning. Stores et al. (2007) also suggests that narcolepsy was a mostly rapid eye movement sleep disorder with onset normally from the second decade however frequently in earlier childhood, and also indicates that it was distinguished through blend of excessive sleepiness particularly sleep attacks, cataplexy, hypnagogic hallucinations, and sleep paralysis. In addition, previous research indicates that narcolepsy seems to be a dominantly inherited state in children, also is still a clinical diagnosis (Weinberg and Emslie 1990). They also indicate that the clinician should ask especially for these signs. 
Piper, Ogden, Simoyan, Chung, Caggiano, Nichols, and McCall (2018) shows to utilize patterns reflect a blend of elements such as the growing ADHD diagnostic standards and usage of their DSM-5 in the US, rates of off-label employ for other signs like obesity and narcolepsy, restricted access to non-pharmacological, however proof-based, treatments such as behavioural parent training and behavioural classroom management, patent expirations, the ease of once daily dosing, along with the socio-legal, economic, or ethnic traits which affect decision-making regarding the comparative dangers and injuries for these agents. Not only that, but indicates another research was required to measure the part of the stimulant growth that is because of ADHD vs. obesity, narcolepsy, depression, non-ADHD cognitive improvement, or alternative off-label usage.

\subsection{Complex Conditions with Cataplexy}

As for the complex disorders, narcolepsy has been discussed related to cataplexy. Narcolepsy with cataplexy was distinguished by daytime sleepiness, cataplexy, sleep paralysis, hypnagogic hallucinations and disturbed nocturnal sleep (Plazzi, Pizza, Palaia, Franceschini, Poli, Moghadam, Cortelli, Nobili, Bruni, Dauvilliers, Lin, Edwards, Mignot, and Bhatia 2011). Human narcolepsy with cataplexy is a neurological disorder, which grows because ofdeficit in hypocretin producing neurons in the hypothalamus (Fontana, Gast, Reith, Recher, Birchler, and Bassetti 2010). Latestimplementations in narcolepsy studyhelp the hypothesis of narcolepsy being an immune-mediated disease. Plazzi et al. (2011) calls attention to the fact that children with narcolepsy frequentlyexhibit complicated abnormal motor behaviours near to disease onset that do not fulfil the classical description of cataplexy, and it analyses motor attributes in 39 children with narcolepsy with cataplexy. It shows that patients with narcolepsy with cataplexy exhibited a complicated array of "negative" (hypotonia) and "active" (ranging from perioral movements to dyskinetic-dystonic movements or stereotypies) motor disturbances. They propose that paediatric narcolepsy with cataplexy often co-occurs with a complex movement disorder at disease onset, a phenomenon that might vanish later in the route of the illness.

Considering that the demand for a cataplexy step was specific to narcolepsy, and cataplexy was presently evaluated in adults utilizing a daily diary, adjustment of a diary format to more transparently specify how to identify cataplexy utilizing child-friendly language might existent the most suitable approach for analysing this sign (Benmedjahed, et al. 2016). By comparison, EDS can be a feature of different states, and isn't unique for narcolepsy. Of accessible steps of EDS, the ESS was the most commonly employed and was supported in adults having narcolepsy. Therefore, through other paediatric EDS steps can be found, the ESS will signify a step which will be easily modified and standardized to ensure it was child friendly. The principal advantage is using a well-documented amount of EDS throughout the entire age range, from young children to adolescents, as well as adults of all ages.

\subsection{Difficulties in Schooling}

Wise (1998) suggests narcolepsy in childhood may be probably under recognized in this population people, and mental and academic issues were nearly worldwide in children with narcolepsy, and management plans must deal with these fields. Pertinent and precise details regarding narcolepsy ought to be madeaccessible to the sufferer, relatives, schools, companies, and educational specialists. Narcolepsy can be used with achievement both in school also at the work-place, however schools must be supported to organize suitable programs for children with narcolepsy, and career options ought to take note of the probable dangers resulted by immoderate daytime sleepiness and cataplexy (Zeman, Britton, Douglas, Hansen, Hicks, Howard, Meredith, Smith, Stores, Wilson, and Zaiwalla 2004). Difficulties confronted by sufferers who have narcolepsy contain societal stigma connected with this disorder, problems in acquiring an education as well as maintaining 
work, a decreased standard of life and socioeconomic effects (Kornum et al. 2017).

Stores, et al. (2007) indicates that clinicians and others accountable for the care of these children require to be conscious of the significance of early intervention, discovery, also, ideally, the precautious of those issues. Wise and Lynch (2001) indicates that key signs of narcolepsy were alike in children in comparison to adults, however expression might differ because of more serious symptoms, maturational elements, along with the substantial effect of signs on behaviour and academic operation. Employing diagnosis of narcolepsy in children can be hard and needs a comprehensive background succeeded by polysomnography and the Multiple Sleep Latency Test were urged, and direction entails a detailed strategy, involving sufferer as well as family education and psychological aid; behavioural approaches, including well sleep hygiene and planned naps; along with pharmacologic intervention.

In 2009 and 2010, a widecategory of Finnish children and adolescents got narcolepsy after the vaccination movement to stop swine flu pandemic ((Karjalainen, Nyrhilä, Määttä, andUusiautti 2014). The aim of the studyis to analyse how narcolepsy whichevolved from the swine flu vaccination was affected the school going, school work, and its fluency of six elementary school pupils, and how helpful the support given have beendiscerned. The relations between school settings and the actual conditions of students with narcolepsy as a research for the educational needs and demand has been noticed, but this research is one of few cases for the widesurveyofthe physical conditions of the narcoleptic students.Additionally, in response to severe problem which originated in the schools, this study focusing what type of a learning environment school offers to children with narcolepsy is critical for the treatment for them. Karjalainen et al. (2014) shows that the realization of the operative curriculum has also analysed through the point of view of tripartite help and segregation of learning, and discusses that narcoleptic signs wereserious over the participants that had confronted all their activities and environments, especially in the beginning of the illness. There are many risk factors and problems in school due tostudents' narcolepsy. The probabilities of melding these children's learning environments were to be analysed.

With regards to the students' research had demonstrated that sleep was essential for their performance in schools. Evaluations were created of behaviour, mood, quality of life (QoL), and also educational aspect. Study conducted by Dodel et al. (2006) shows a reduced HRQoL in sufferers of narcolepsy. Dodel et al. (2006) suggests that the reduction in HRQoL was comparable to that in another chronic neurologic illness, like Parkinson's disease and multiple sclerosis, also substantially decreases standard of life from these sufferers, which not only drug therapy had an influence on the HRQoL from narcoleptic sufferers but additional steps, like supporting sufferers keep their functioning and personal relationships, might also have a significant effects.

Paruthi and Kotagal (2016) suggests that the narcoleptic children have lesser health-related standard of life, energy, usual well-being, weaker self-image, low contact with parents, and reduced school operation, when compared to control children. The chapter reveals school difficulty documented in children with narcolepsy in 6 main points as 1) falling asleep 2) weak grades/academic functionality despite regular IQ, 3) societal conflicts with teachers and peers, 4) behaviour and psychological difficulties, 5) problem in creating friends, and 6) more absences from schools. Narcoleptic adolescents also had reduced standard of life index, lesser physical well-being, and lesser friends and leisure activities compared to control children. Depression was the element that most influenced standard off life. Interestingly, there are not any distinctions in health-related standard of life while comparing treated versus non-treated narcoleptic sufferers. 
With regard to the function of schools and professional staffs, school psychologists may efficiently evaluate sleep behaviours within just a couple of minutes also could frequently enhance pupils' sleep using short involvements (Laracy, Ridgard, and DuPaul 2015). Laracy et al. (2015) reviews the significance of sleep and gives school psychologists using plans for evaluation and involvement, and in addition gives a brief discussion of several sleep disorders (e.g., obstructive sleep apnoea, parasomnias, restless legs syndrome, narcolepsy) that may require referral to a medical provider. After diagnosis, it might be difficult for pupils to clearly communicate precisely how their signs and medications influence their function (Flygare 2016). Since the pupil adapts to signs and new therapies, it might take time to discover a better timetable and accommodations that best fulfil the pupil's requirements. Flygare (2016) reviews potential accommodation concepts, locating practical methods to enhance their sufferer's capacity to achieve at school.

Though presently obtainable stimulant drugs could be useful to some degree, the cornerstone of management was education, psychological and academic assistance, as well as cautious follow-up as time passes. In spite of remarkable development recently in understanding the aetiology of human narcolepsy by molecular genetic analyses, the disease stays a chronic also frequently disabling illness with significant effect on the life of children and their families. The general aim for handling childhood narcolepsy was to help the child and family in attaining optimal standard of life (Wise 1998, Wise andLynch 2001). Most of the participants noticed residual daytime exhaustion and/or sleepiness despite therapy, and any participants noticed they were not able to perform at work or school and also they would like due to narcolepsy signs (Maski et al. 2017).

Maski et al. (2017) imply that narcolepsy understanding attempts must be directed toward parents, paediatric health care providers, school specialists, along with children/adolescents which illness burden is high due to issues with tiredness, cognition, along with determination of residual signs in spite of therapy.

\section{IV.CONCLUSIONS}

In conclusion, the authors would like to state the succeeding points. First, it is required to carry additional study into psychological as well as emotional effects of children with narcolepsy in the school settings. Although clinical condition of narcolepsy has been noticed, this does not mean that it has practiced largely in the schooling to deal with these types of problems. Consequently, primary points and supporting practices required to progress for accommodation in meeting the special needs of the school-aged children. There must be additional examination of this topic.

Second, developing the assessment tools for children with narcolepsy and its modification needs to be promoted and researched in the context of education and psychology. Practitioners engaged in the support for students with narcolepsy have to initiate the assessment on a relatively small scale as well as slowly enlarged its reach. Their practice are to be informed by accumulated understanding and information that could assist revise pedagogical and psychological supporting styles, and evolve teachers and other professionals concerning to schooling. Mutual assessment could be made regarding how to adjust it for the patients' needs in daytime in schooling.

Third, researches have to be in a greater effort to analyse the special educational needs of students with narcolepsy. For example, the patients' rate for narcolepsy in Japan is higher than Europe and North American Areas (Itoh 2013). It was partly understandable that educators and researchers were caught up with responding to problems and issues in a domestic context. But, translating thoughts and practices into the international context will surely support students with narcolepsy to reflect upon their practices and to deepen their knowledge of students' needs. Therefore, wider surveys and their 
exchange of knowledge and information have to be strengthened, specificallywith regard to educational needs related to narcolepsy.

\section{NOTE}

This study has been funded with Grant-in-Aid for Scientific Research from Japan Society for the Promotion of Science, Grant Number 18K02433. The funders had no role in study design, data collection and analysis, decision to publish, or preparation of the manuscript.

\section{REFERENCES}

1. Abraham, A. D., Cunningham, C. L., \&Lattal, K. M. (2012) Methylphenidate Enhances Extinction of Contextual Fear. Learning \& Memory, 19(2), 67-72

2. Benmedjahed, K., Wang, Y. G., Lambert, J., Evans, C., Hwang, S., Black, H., \& Johns, M. (2016) Assessing sleepiness and cataplexy in children and adolescents with narcolepsy: a review of current patient-reported measures. Sleep Medicine, 32, 143-149

3. Blackwell, J. E., Alammar, H. A., Weighall, A. R., Kellar, I., \& Nash, H. M. (2017) A systematic review of cognitive function and psychosocial well-being in school-age children with narcolepsy. Sleep Medicine Reviews, 34, 82-93

4. Boland, A., Cherry, M. G., \& Dickson, R. (2013). Doing a Systematic Review: A Student's Guide. New York, SAGE.

5. Cosgrove, M. S. (2002) Sleeping Beauty in the Classroom: What Do Teachers Know about Narcolepsy? Journal of Early Education and Family Review, 9(4), 31-37

6. Dodel, R., Peter, H., Spotteke, A., Noelker, C., Althaus, A., Siebert, U., Walbert, T., Kesper, K., Becker, H. F., \& Mayer, G. (2006) Health-related quality of Life in patients with narcolepsy. Sleep Medicine, 8(7-8), 733-741

7. Dwivedi, G. N., et al. "A Study of Childhood and Adolescent Obesity with Special Reference to Effect of a Combined Intervention Therapy." International Journal of Medicine and Pharmaceutical Science (IJMPS) ISSN (P) (2016): 2250-0049.

8. EZEMA, PA. "THE PLACE OF ENGLISH AND INDIGENOUS NIGERIAN LANGUAGES IN EARLY CHILDHOOD GROOMING." International Journal of English and Literature (IJEL) 3.4, Oct 2013, 87-92

9. Ferri, R., DelRosso, L. M., Aricò, D., Zucconi, L. Picchietti, D., Pizza, F., Plazzi, G., Manconi, M., \& Bruni, O. (2018) Leg movement activity during sleep in school-age children and adolescents: a detailed study in normal controls and participants with restless legs syndrome and narcolepsy type 1. Sleep, 41(4), zsy010

10. Flygare, J. (2016) Succeeding in School and in the Workplace with Narcolepsy. In Goswami, M., Thropy, M. J., \&PandiPerumal, S. R. (eds.) Narcolepsy: A Clinical Guide, Second Edition. New York. Springer.

11. Fontana, A., Gast, H. R., Walter, R. M., Birchler, T., \&Bassetti, C. L. (2010) Narcolepsy: Autoimmunity, Effector T Cell Activation Due to Infection, or T Cell Independent, Major Histocompatibility Complex Class II Induced Neuronal Loss? Brain, 133(5) 1300-131

12. HYE, LEE KYOUNG, and KIMSUK JA. "AN ANALYSIS OF RESEARCH TRENDS ON EARLY CHILDHOOD ARTS EDUCATION FOR ARTS CONVERGENCE EDUCATION." International Journal of Educational Science and Research (IJESR) 7.2, Apr 2017, 141-148

13. Itoh, H. (2013) SuiminSyogai (originally in Japanese. Sleep Disorders) inMiyazaki, S. \& Sato, S.Suimin to Kenko (originally in Japanese. Sleep and Health). Tokyo, Open University Press Japan. 
14. Karjalainen, S., Nyrhilä, A. M., Määttä, K., \&Uusiautti, S. (2014) Going to School with Narcolepsy-Perceptions of Families and Teachers of Children with Narcolepsy. Early Child Development and Care, 184(6), 869-881

15. Kornum, B. R., Knudsen, S., Ollila, H. M., Pizza, F., Jennum, P. J., Dauvilliers, Y., \& Overeem, S. (2017) Narcolepsy. Nature Reviews Disease Primers, 3, e:16100. Retrieved from https://doi.org/10.1038/nrdp.2016.100

16. Laracy, Seth D.; Ridgard, Tamique J.; DuPaul, George J.(2015) Sleep and Functioning: Guidelines for Assessment and Intervention. Communique, 43(8),1-18

17. Mohamed, A.D. (2016) The Effects of Modafinil on Convergent and Divergent Thinking of Creativity: A Randomized Controlled Trial, Journal of Creative Behavior, 50(4), 252-267

18. National Institute on Drug Abuse, National Clearinghouse for Drug Abuse Information (1974)

19. Amphetamine. Report Series 28(1), Rockville, National Clearinghouse for Drug Abuse Information.

20. Nevsimalova, S., Buskova, J., Kemlink, D., Sonka, K., \&Skibova, J. (2009) Does age at the onset of narcolepsy influence the course and severity of the disease? Sleep Medicine, 10(9), 967-972

21. Paruthi, S., \&Kotagal, S. (2016) Narcolepsy in Childhood. in Goswami, M., Thropy, M. J., \&Pandi-Perumal, S. R. (eds.) Narcolepsy: A Clinical Guide, Second Edition. New York. Springer.

22. Piper, B.J, Ogden C.L., Simoyan, O.M, Chung, D.Y., Caggiano, J.F., Nichols, S.D., \& McCall, K. L. (2018) Trends in use of prescription stimulants in the United States and Territories, 2006 to 2016.,PLoS ONE 13(11): e0206100. Retrieved from https://doi.org/10.1371/journal.pone.0206100

23. Plazzi, G., Pizza, F.,Palaia, V.,Franceschini, C.,Poli, F., Moghadam, K. K.,Cortelli, P., Nobili, L., Bruni, O.,Dauvilliers, Y., Lin, L., Edwards, M.,Mignot, E., Bhatia, K. P. (2011) Complex Movement Disorders at Disease Onset in Childhood Narcolepsy with Cataplexy. Brain, 134(12), 3480-3492

24. Sattler, S., Sauer, C., Mehlkop, G., \&Graeff, P. (2013) The Rationale for Consuming Cognitive Enhancement Drugs in University Students and Teachers. PLoS ONE, 8(7): e68821. Retrieved from https://doi.org/10.1371/journal.pone.0068821

25. Shankar A, Syamala S, Kalidindi S (2010) Insufficient Rest or Sleep and Its Relation to Cardiovascular Disease, Diabetes and Obesity in a National, Multiethnic Sample. PLoS ONE 5(11): e14189, retrieved from https://doi.org/10.1371/journal.pone.0014189

26. SHAMKHY, DR MAHMOOD SWADY, and DR MAZIN MOHAMMAD JAWAD AL-MUSSAWY. "OUTCOME ANALYSIS AND OUTCOME PROGNOSTIC FACTORS OF TRAUMATIC BRAIN INJURY IN CHILDHOOD." International Journal of Medicine and Pharmaceutical Science (IJMPS) 9.4, Aug 2019, 35-48

27. Stores, G., Montgomery, P., Wiggs, L. (2007)The Psychosocial Problems of Children with Narcolepsy and Those with Excessive Daytime Sleepiness of Uncertain Origin. Journal of the American Academy of Child \& Adolescent Psychiatry, 46 (4), 488

28. Weinberg, W. A., \& Emslie, G. J. (1990) Attention Deficit Hyperactivity Disorder: The Different Diagnosis., Rockville, National Institute of Mental Health.

29. Wise, M. S.(1998) Childhood narcolepsy, Neurology $50 \quad(2 \quad$ Suppl 1$)$ S37-S42, retrieved from https://doi:10.1212/WNL.50.2_Suppl_1.S37

30. Wise, M. S. \& Lynch, J. (2001) Narcolepsy in children, Seminars in Pediatric Neurology, 8(4), 198-206 
31. Zeman, A., Britton, T., Douglas, N., Hansen, A., Hicks, J., Howard, R., Meredith, A., Smith, I., Stores, G., Wilson, S., \&Zaiwalla, Z.(2004) Narcolepsy and excessive daytime sleepiness. British Medical Journal, 329(7468), 724-728 